\title{
Accessibility and viability: A complex adaptive systems approach to a wicked problem for the local food movement
}

\author{
Connie H. Nelson ${ }^{a *}$ and Mirella L. Stroink ${ }^{\mathrm{b}}$ \\ Lakehead University
}

Submitted October 3, 2013 / Revised January 25, April 16, and May 17, 2014 / Accepted May 17, 2014 /

Published online September 16, 2014

Citation: Nelson, C. H., \& Stroink, M. L. (2014). Accessibility and viability: A complex

adaptive systems approach to a wicked problem for the local food movement. Journal of

Agriculture, Food Systems, and Community Development, 4(4), 191-206.

http://dx.doi.org/10.5304/jafscd.2014.044.016

Copyright (C) 2014 by New Leaf Associates, Inc.

\begin{abstract}
There is a tension between enhancing vulnerable people's access to local nutritious food and ensuring viable incomes for local farmers. This tension arises as a result of interactions and processes scaling outward to the broad level of economic and political ideologies (Ikerd, 2005; 2012). We suggest that by conceiving of this tension as a wicked problem and employing complex adaptive systems theory, we create space in which community members are empowered to share existing knowledge and develop new

\footnotetext{
a* Corresponding author: Connie H. Nelson, Ph.D., Food Security Research Network, School of Social Work, Lakehead University; 955 Oliver Road; Thunder Bay, Ontario P7B 5E1 Canada; +1-807-767-0480; cnelson@lakeheadu.ca

b Mirella L. Stroink, Ph.D., Department of Psychology; Food Security Research Network, Lakehead University; 955 Oliver Road; Thunder Bay, Ontario P7B 5E1 Canada; mstroink@lakeheadu.ca
}

knowledge as they innovate potential solutions and discuss constructive change. We introduce this space as the beginnings of a dialogue-driven, shared journey through four features of the back loop of the adaptive cycle. Drawing on this theoretical foundation as well as Block's (2009) structure for creating a community of belonging, we hosted two one-half-day-long events for 90 community members, including farmers, foodinsecure people, government representatives, and public agencies. This bottom-up, emergent approach to developing new system patterns may ultimately transform the domain of the problem and present viable alternative futures, which then may be adapted to the local reality and enhance community well being.

\section{Keywords}

complex adaptive systems, community capacity building, food accessibility, food security, local food systems, wicked problems 


\section{Introduction and Purpose}

There is a tension between enhancing vulnerable people's access to local and nutritious food and ensuring viable incomes for local farmers (Fischer, Hamm, Pirog, Fisk, Farbman, \& Kiraly, 2013; Forbes \& Harmon, 2008; Hinrichs \& Kremer, 2002; Knezevic \& Nelson, 2013; Landman et al., 2009). This tension arises as a result of interactions and processes scaling outward to the broad level of economic and political ideologies (Ikerd, 2005; 2012). Despite the challenges presented by this context (Ballamingle \& Walker, 2013; Matson, Sullins, \& Cook, 2013; Nelson \& Stroink, 2011; 2012), the local food movement has been successful in increasing the availability and variety of locally grown foods in many communities. The purpose of this paper is to apply complex adaptive systems theory to explore this tension as a wicked problem through Block's applied framework for community-building conversations. While we present some limited evidence of the efficacy of this wicked problem process, our primary focus is to explore the process itself as a possible way of moving forward with challenges like the tension between local food affordability and farmers' incomes that often seem contradictory and impossible to resolve. We view this paper as a catalyst to explore the appropriateness of using a wicked problem approach to conceptualize the complex issues that arise as alternative food systems emerge dynamically through the complex interactions of people on every level from the individual to the political, economic, and societal.

As the local food system emerges as an alternative food system within our global, commoditybased economy, local foods are often too economically costly for a large portion of society (Lappé, Clapp, Anderson, Broad, Messer, Pogge, \& Wise, 2013; People's Food Policy Project, 2011). Locally produced food may be more costly due to the economies of scale at the farm level. Farms supplying local food direct to consumers are smaller on average, with higher per unit costs. In addition, there is a long history of a great variety of government social and ecological subsidies that support a large-scale food system that can lower the costs of mass-produced food. The higher cost of local food presents a complex challenge for those on the grassroots level of the local food movement, who are often motivated by concerns with environmental protection and enhancing the local economy, as well as with social justice and equity (Nelson \& Stroink, 2013).

This issue of enhancing vulnerable people's access to local nutritious food while ensuring viable incomes for local farmers has been the subject of some discussion (Forbes \& Harmon, 2008; Knezevic \& Nelson, 2013; Landman et al., 2009; McEntee \& Naumova, 2012). Utilizing complex adaptive systems theory, we sought to harness the capabilities and capacities of community members, including both vulnerable people and farmers, to share and develop knowledge as they innovate potential solutions themselves. While no obvious solution to this issue currently exists, our approach may present a suitable framework within which to conceptualize the issue and a method with which to seek community-driven solutions to intractable and complex issues. Thus, we emphasize that our focus is on elucidating the process of a wicked problem approach through a complexity perspective using Block's (2009) foundational approach to community capacity building.

\section{Wicked Problems and Complex Adaptive Systems Perspective: The Theoretical Framework}

There are two key questions at the heart of this issue: (1) How can communities enhance vulnerable people's access to local nutritious foods? and (2) How can communities ensure that emerging local farmers are able to earn viable incomes? Both of these questions, in and of themselves, address complex and interacting issues at the social, environmental, and economic levels such as transport, loss of scale economies, and production methods. For example, in Canada as elsewhere, vulnerable people's access to local nutritious foods has been negatively influenced by a steady retrenchment of a social safety net including decreased levels of, and heightened eligibility restrictions for, both social assistance and EI (employment insurance), insufficient minimum wage standards, and increasing mismatch between worker skills and job growth areas (Federation of Canadian Municipalities, 2010). Moreover, creating viable levels of income 
for emerging young farmers involves serious challenges, including the cost of land, lack of space for new farmers and for alternative markets within supply management systems, limited regional processing and distribution infrastructure, and regulatory barriers affecting small- and medium-scale producers (Baker, Campsie, \& Rabinowicz, 2010; Landman et al., 2009).

Resolving the tensions between vulnerable people's access to local nutritious foods and creating a viable income for emerging young farmers has no obvious solution and may be best conceived as a wicked problem (Conklin, 2005; Head, 2008; Rittel \& Webber, 1973). A wicked problem may be described as a problem, typical of social planning and policy situations, that is difficult or impossible to solve because there is no one socially agreedupon correct solution and no consistent or undisputed set of expectations or qualifications for determining optimal solutions (Batie, 2005; Rittel \& Webber, 1973). Bringing together the complex, open-system contexts shaping both sides of this issue - food systems and social-economicpolitical systems - can assist in discerning the dynamic scope of the causal webs producing this wicked problem. By approaching our analysis as a wicked problem and abandoning linear attempts at finding a "solution," space is created for discussing constructive possibilities. Rittel and Webber (1973), referring to "second generation" systems approaches to problem solving, recognize that wicked problems cannot be solved by classical approaches that involve sequential steps, from gathering information through synthesizing to solving. Instead, these problems must adopt a dialogue-based approach, where a problem and its solution emerge gradually among participants, through incessant "critical argument" (p. 162). In the planning field, Kunz and Rittel (1970/1979) developed a technique called the Issue-Based Information System to address wicked problems through dialogue. Since then, similar approaches have been developed in the community development literature (Born, 2012; Brown, Harris, \& Russell, 2010; Diers, 2004; Headwaters Group, 2012; Roberts, 2000). Manson (2001) recognizes that complex social problems emerge from the dynamics of interacting complex systems, and resolution to a complex problem must engage everyone's participation.

While wicked problems and complex adaptive systems (CAS) theory developed along complementary but parallel pathways, they share origins in a complexity perspective. As such, CAS theory provides a clear perspective for understanding the wicked problem concept, especially in light of the complex social and ecological systems out of which wicked problems tend to emerge (Goldstein, Hazy, \& , 2011; Gunderson \& Holling, 2002; Holman, 2010; Walker \& Salt, 2006). We draw on a CAS theory perspective to describe the food system, as well as to describe the process through which knowledge and innovation emerge in community gatherings.

Our research to date on emerging local food systems has revealed a diversity of creative approaches to local food production and distribution. Interviews with those behind such local food initiatives reveal concerns with environmental sustainability and social justice. We describe these local food initiatives as self-organizing and driven by volunteers in the absence of sustaining operating funds (Nelson \& Stroink, 2013). We have argued elsewhere that the food system can be understood to be a complex adaptive system (Stroink \& Nelson, 2013). Specifically, local food initiatives, their networks of people, as well as the collective space of the local food system and the broader overall food system can each be understood to be a complex adaptive system, nested within systems on higher scales and containing systems on lower scales, all interacting with one another in a dynamic and emerging manner. Conceptualizing the food system through this lens allows for a number of novel insights.

For example, Stroink and Nelson (2013) argued that the development of the local food system can be mapped onto the adaptive cycle (Holling, 1986). The adaptive cycle (Figure 1) is a representation of change over time in complex adaptive systems. These systems tend to move through a forward loop of increasing structuredness to a point, known as rigidity trap, when the system's capital is completely consumed in the maintenance of those structures, with relatively little available for new growth or innovation. The 
Figure 1. The Adaptive Cycle of Growth and Release (based on Holling, 1986, 2001; see also Stroink \& Nelson, 2013)

\section{Forward Loop:}

- Focus on efficiency and growth

- Increasing structure and control over resources

- Declining capacity to adapt to change

- Increasingly vulnerable to rigidity trap

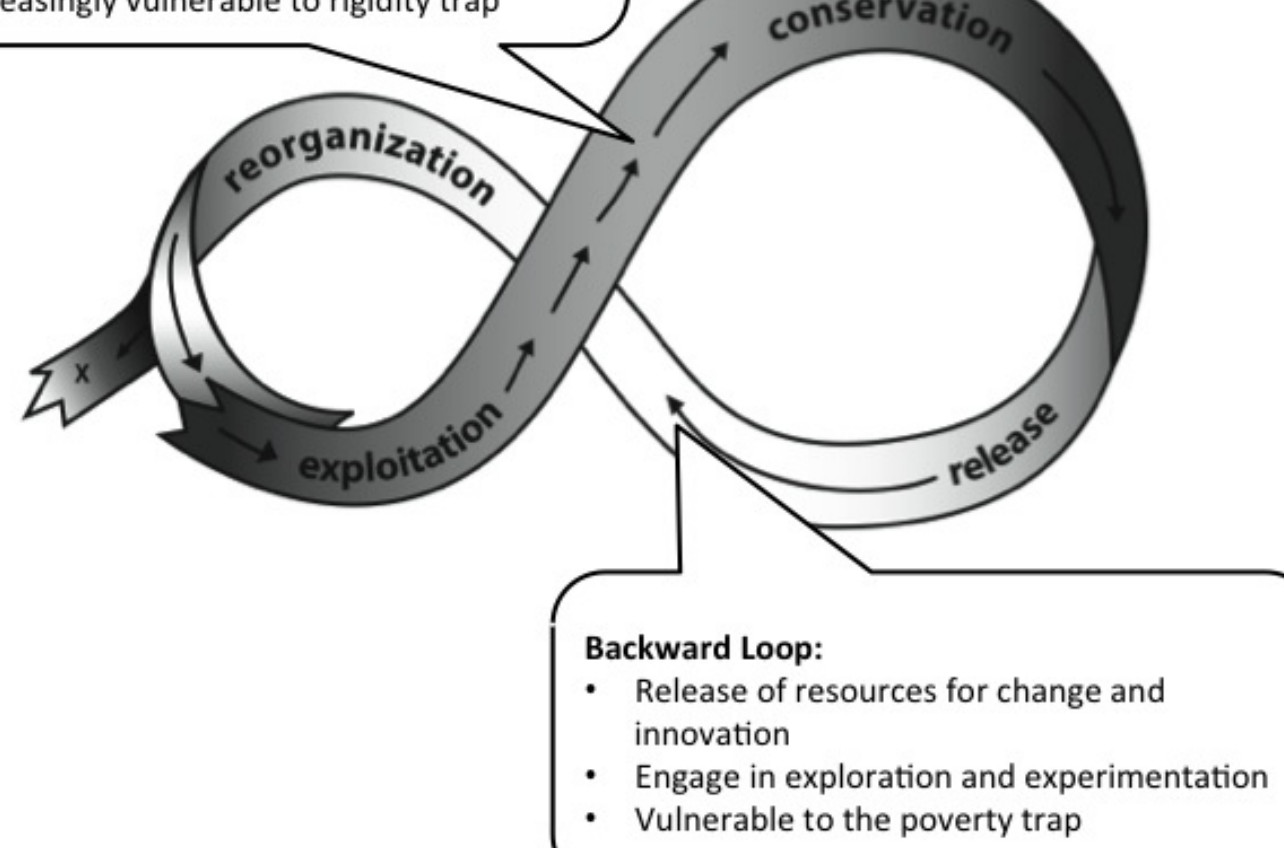

structure of a complex adaptive system is its order, which gives shape to and increasingly focuses the patterned behaviors of the system into specified pathways. This structure holds the behavioral pattern of the system into place and becomes increasingly formalized throughout the forward loop. The back loop is characterized by the collapse of this structure and the release of capital to be available again for novel combinations of diverse elements and experimentation with new forms of structure. Stroink and Nelson (2013) argued that the mainstream food system may be viewed at the height of the forward loop, with local food initiatives emerging within the backward loop or the very beginnings of a new forward loop. Those who create local food initiatives may attempt to use small amounts of capital released from the dominant system (and brought in from other systems, such as academic or health) to support the emergence of creative and diverse approaches to the local food system.

It is important to note that human communities are organized as complex adaptive systems. Understanding them as such leads to the recognition that bringing together diverse individuals within the community (increasing network connectivity) increases the possibility of innovation and the emergence of new knowledge (Könnölä, Brummer, \& Salo, 2007). Thus the previously studied northern Ontario (Canada) food initiatives have emerged as a result of community-level connectivity that has self-organized in diverse ways to 
yield an abundance of possibilities. This diversity and connectivity uniquely blends local resources to enable actors to create vibrant community-based food systems. This complexity-based perspective on community and innovation appears consistent with recent advances in the community development literature (Block, 2009; Born, 2012; McKnight \&, 2010). Together, they recognize that it is the community itself that will form the alternative dynamics that may ultimately address this wicked problem of how a community can enhance access to nutritious local food and support the viability of emerging new farmers.

\section{The Gatherings}

Drawing on this theoretical foundation, we developed two half-day events that brought together 90 community members, including farmers, vulnerable people, staff members of government and public agencies that provide emergency food programs, policy advocates, and staff of programs serving vulnerable peoples (Food Security Research Network [FSRN], 2013). Many participants had multiple roles, such as students who were also vulnerable persons, students who were farmers, and students who worked for public and government agencies. For the present purposes, we considered vulnerable people to include those requiring employment insurance or social assistance, as well as the working poor, people living with various disabilities, and students struggling with high postsecondary educational costs. We followed Block's (2009) structure for creating this community of belonging: we named the event a community gathering; we paid attention to public space and the representation of the two half-day events in the invitation; we centered conversations on possibility, ownership, dissent, commitment, and gifts. We also used the speed networking and World Café approaches, as these are believed to liberate participants from the constraints of existing mental structures (Brown \& Isaacs, 2005; Lipmanowicz \& McCandles, 2013, 2014). Community service learning (CSL) university students from two macro community theory courses participated in the Gatherings and also wrote reflective essays on their experiences. As stated earlier, while the focus of this paper is on the wicked problem process, sev- eral of the student observations from both days are included to provide clarity to the central themes that emerged through these Gatherings.

By paying attention to language and naming our events "Gatherings," we attempted to open up space where every participant had voice and the specific content of each gathering arose from within, rather than from a predetermined agenda. In addition, nine months prior to the two Gatherings we sought out a public and accessible site that was welcoming in appearance, had nearby bus access, and was close to a food court and shopping mall. The gathering site was city-approved for a maximum of 45 persons, so this became the determining number for each of the two Gatherings. This group size also fit Block's (2009) belief that the small group is the unit of transformation, rather than a community-wide public meeting. The students created the invitation in a fourth-year macro community theory course as part of their CSL experience. The invitation followed Block's invitational approach of being clear about who is invited so as to ensure diversity by purposefully extending the invitation to people who were not used to being together, naming the possibility about which the gathering was convening, emphasizing freedom of choice in deciding whether to attend, describing what the gathering was about, and making the invitation as personal as possible. Specific wording included naming the event a Community Gathering, enhancing the welcoming atmosphere by indicating local food would be served, and raising the invitational question: $W$ ant to add your thoughts to how our community enhances access and availability of local food to vulnerable community members and also ensures economic viability for our local producers and processors?

Besides widely circulating a poster, several "mini-coffee gatherings" were held six and one months before the Gatherings with local community leaders recognized for their place-based work with vulnerable peoples. From these mini-gatherings, many logistics were worked out, such as the appropriate time of day for the Gatherings, city bus schedules for easy access, the use of round tables for interactive discussions, and the decision to only identify participants by first name on nametags. The latter two decisions were effective in mini- 
mizing hierarchical differences and presenting an environment in which all voices were welcome. After the Gatherings, students reported that other than the few participants who self-identified, they were unable to identify the specific representation of the participants. The advisory committee confirmed that there were indeed vulnerable people at the Gatherings.

On the day of each Gathering, the participants entered a room where smiles and greetings of welcome were shared, heightened by the warmth of the room itself with large student foodie posters on the walls, old wooden floor, walls painted in subdued and warming shades of purple, abundant natural light from large windows and several sky lights, and round tables that could each seat eight to 10 people.

After everyone was seated, the convening leader restated the invitation, explaining why we were all gathered together to search for possibilities in creating more affordable and accessible local food to vulnerable populations and where farmers have a sustainable income. The convening leader spoke to everyone without the use of props - no PowerPoint or slides and she was genuine in making this an open discussion where we could explore gifts and possibilities. It was not some gathering that was slapped together because we had to for our curriculum; it was heartfelt and engaging, because it had meaning. [Student description of the Gatherings]

An intellectually liberating structure called speed networking was then introduced in both Gatherings. Everyone was asked to find someone unfamiliar in the room and share with each other for seven minutes what they hoped would be created by coming together for these Gatherings. This sharing through speed networking was repeated twice for each of the two Gatherings. This approach had several advantages: eager talkers had an opportunity to immediately express their views; those who were a bit shy had the opportunity to engage and express their ideas in one-to-one dia- logues; and everyone had a chance to "practice" articulating ideas as a "trial run" for sharing their thoughts with the larger group. This also allowed participants to get to know others without having to use formal introductions that would encourage labeling. By using the speed networking exercise, we encouraged all participants to have a voice.

Next the group was asked to help themselves to regionally sourced food prepared and presented by a local city caterer. The convening leader then asked the participants to come back to one of the tables and spend 20 minutes discussing with each other "How they create food security for themselves." This approach encouraged an atmosphere of equity as everyone engages on a daily basis in acquiring food. The convening leader provided examples as a catalyst for further interactive discussions: "My neighbor has a garden and shares with me," "I take my family to eat dinner once a week at my mother-in-law's house," "I carefully watch for food sales." These examples legitimized everyone's approach and opened up space to keep the back loop of the adaptive cycle operating in releasing creative ideas.

There were several creative ideas that we brainstormed as partners, regarding how our community currently puts food on our tables. Some of these ideas include: swapping with neighbours, collective kitchens, dietician involvement, community gardens, gleaning, farmer's market, family and friends' gardens. One that stood out for me in the group discussion, which I had not thought of was hunting. [Student reflection]

Next, participants at each table shared their ideas with the larger group of how to be more food secure. Each table was equipped with a flip chart and colorful sticky notes for posting their ideas. From these presenting ideas, as depicted in Figure 2, four major themes were selected for a World Café exercise (Lipmanowicz \& McCandless, 2014). This process gives all participants a chance in a small-group format to engage in each of the themes. Figure 2 summarizes the specific table topics chosen by the participants under each of the 
Figure 2. Enhancing the Local Food Movement: Summary of Participant Responses from the World Café Exercise

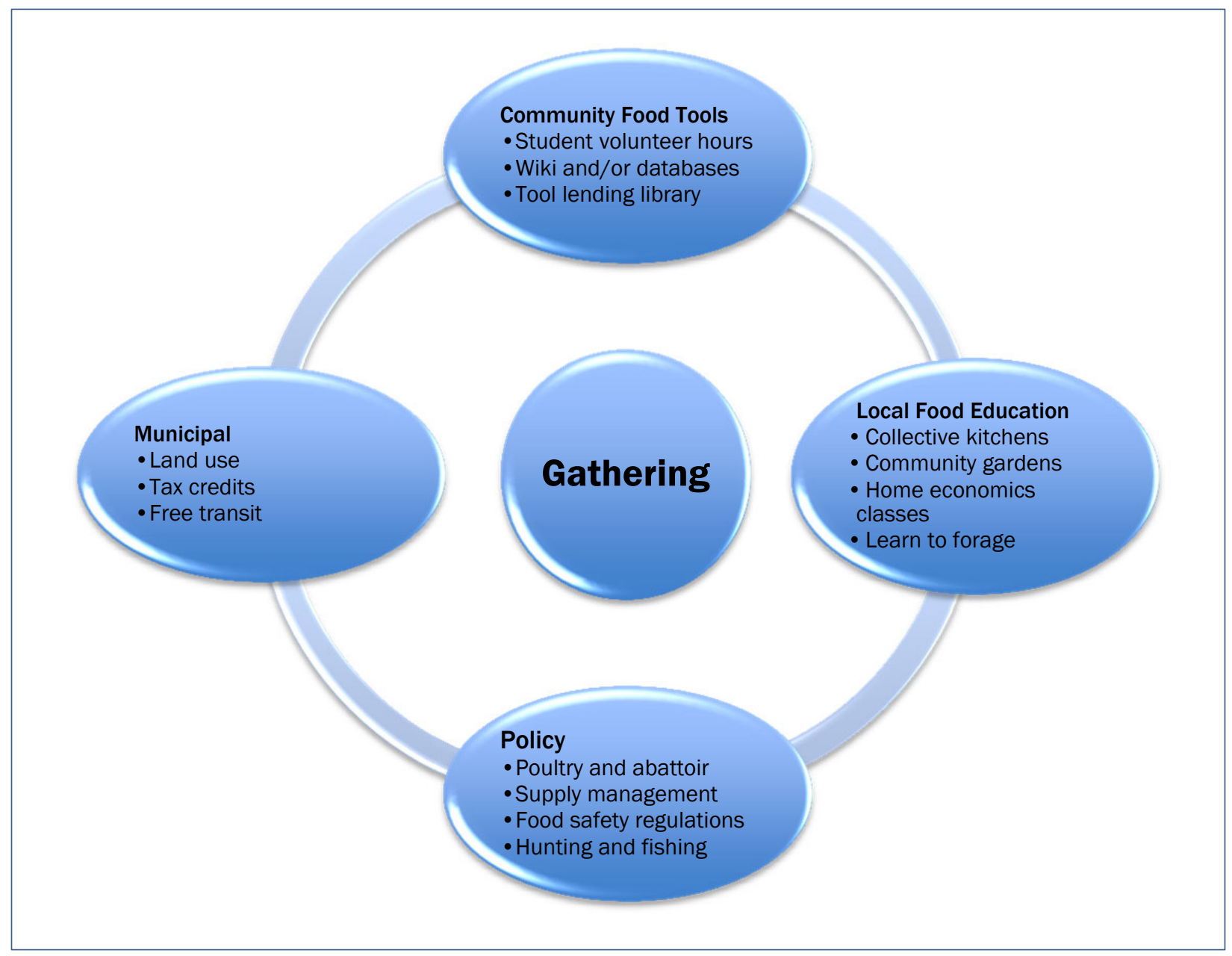

four themes. Examples include barriers and solutions to increasing the use of collective kitchens; participation in community gardens; enhancing the viability of farmer incomes; and barriers and foodrelated policy, including municipal bylaw, zoning, and policy issues.

Each of the two half days ended with each person having one minute to share with all attendees what was one "take away idea they gained from the day."

In asking this question, everyone took a turn sharing their main thought that stood out for them during the Gathering. I found this to be a great summarization of how creative everyone can be when we come together with a diverse group of individuals whom have never met before. For myself, it refreshed my memory of important points that I would like to take away with me. I hope that some of these ideas will stick with me in my work and daily life. This Gathering has created a consciousness for me when purchasing foods and has got me thinking of how I can assist in making my own small changes in our community. [Student reflection]

\section{Discussion}

We designed the space for the Gatherings very carefully so that the members of the community engaged in the process could begin a dialogue that 
may ultimately lead to action to address this wicked problem. The deliberate assembly of diverse voices and the care we took in creating experiences that opened discussion and minimized the importance of existing mental and social structures resulted in an environment that supported the sharing of knowledge and the capacity for innovation (Weber \& Khademian, 2008). This approach to the Gatherings arose through consideration of both Block's (2009) writings on five conversations that enhance community belonging (summarized in Table 1) and key concepts from CAS theory that reveal how wicked problems can be explored and possibly resolved within community.

Wicked problems emerge from the interacting dynamics of multiple open complex systems. Each of these interacting systems has achieved some degree of structure, having moved up the forward loop of its own adaptive cycle. For example, the complex system in which emergency food, social service and health agencies, government ministries, and others interact in the service of vulnerable people is heavily structured by established formal and informal patterns and habits of interaction, roles, and social norms. These structures organize and enable the activities of that system, but also constrain the thinking, idea generation, dialogue, and behavior of those within that system. The complex system that surrounds local farmers, particularly in relation to the wider food system, has likewise achieved some degree of structure (Stroink $\&$ Nelson, 2013). Thus typical attempts to address the wicked problem of the economics of food access and small farm viability seem to emerge from conceiving of these two aspects as two relatively structured entities knocking into one another. Efforts to work with this wicked problem will need to open a safe space in which individuals from both systems can mentally de-structure and play in an emergent new space characterized by diversity, connectivity, and engagement. To destructure in the lens of complex adaptive systems theory and the adaptive cycle is to release mental structure in the form of beliefs, assumptions, and roles in cases where these have become overly rigid and unresponsive or maladaptive in a dynamic context.

This space allows the beginnings of a dialoguedriven, shared journey through the back loop of the adaptive cycle (Figure 1). It begins with (1) the loss of structure typical of the creative destruction or release phase (de-structuring), then (2) embraces the diversity that emerges as people from previously isolated structures begin to connect. It then (3) nurtures this connectivity and (4) engages actively toward the generation of ideas or solutions. Within these four features of the back loop we reveal a different light on Block's (2009) five conversations on community belonging and see how both played out in the Gatherings.

\section{De-Structuring}

One of the hallmarks of CAS theory is the adaptive cycle (Gunderson \& Holling 2002; Holling, 2001). This theory, while originating in biophysical processes, has been viewed increasingly as relevant to illuminating social processes (Daedlow, Beckmann, \& Arlinghaus, 2011; Dooley, 1997; Stroink \&

\section{Table 1. Summary of Block's (2010) Five Conversations for Building Community Belonging}

\begin{tabular}{ll}
\hline Possibility & $\begin{array}{l}\text { A conversation that focuses on building a new future of living well. It is neither a plan nor a dream, but a } \\
\text { declaration that can become a catalyst for transformation. }\end{array}$ \\
\hline Ownership & $\begin{array}{l}\text { A conversation that begins with acknowledging how one has contributed to creating the current } \\
\text { community reality. Subsequently this becomes a stance from which to initiate new action, rather than to } \\
\text { assign blame. }\end{array}$ \\
\hline Dissent & A conversation that opens up space for diversity in beliefs about our collective community future. \\
\hline Commitment & $\begin{array}{l}\text { A conversation that embraces a promise of action for change that is made independent of approval or } \\
\text { reciprocity from others. }\end{array}$ \\
\hline Gifts & $\begin{array}{l}\text { A conversation that focuses on strengths that have the potential for transformation and brings talents } \\
\text { that are currently on the margins into the center. }\end{array}$ \\
\hline
\end{tabular}

Adapted from Block, P. (2009). Community: The structure of belonging. San Francisco: Berrett-Koehler Publishers, Inc. 
Nelson, 2013). A key insight of this perspective is recognizing the importance of the creative destruction phase to the overall resilience of a complex system. In the loss of existing structure, a complex system, whether it is a business or an ecosystem, can adapt to changing circumstances and innovate. A turn through this release phase need not be a total collapse and can be conducted in a managed way so as to protect the essential functioning of the system, even as some of the system's capital is reinvested in new growth. Through simple details such as the use of only first names and no affiliations on nametags, the Gatherings attempted to replicate the experience of releasing structure in a safe space. Another CAS concept relevant here is the ecotone. The ecotone is the area near the edges of two adjoining ecosystems, such as where a forest meets a grassy lawn (Risser, 1995). Because neither system's structure has complete organization at the ecotone, there tends to be an abundance of diverse growth, greater than is seen in either system alone. This is why community psychologists speak of "leveraging the power of the ecotone" when attempting to enhance innovation and growth in communities (Kagan, 2007). By focusing attention and nurturing dialogue at the ecotone between local food and vulnerable people, the Gatherings created a space in which people could play with a momentary "mash up" of structure.

The framework for our wicked problem encouraged participants to experience and engage in all five of Block's community conversations of belonging: possibility, ownership, dissent, commitment, and gifts (Block, 2009). The first of these, possibility, produces a de-structured state of mind in participants. Specifically, the focus for the dialogue is on active engagement rather than on deficit thinking that can keep communities stuck. Possibility is about being and aliveness; rather than making passive declarations of what we think should happen, instead saying what are we going to do. The Gatherings began with a possibility question of "what do we want to create today?" This question focused attention beyond existing structure to a future of possibility. Indeed, this question created a deep conversation where people discussed an abundance of diverse ideas, such as having a traveling food bus full of fresh local produce, either for sale or for donating; more community gardens, especially along bus routes and bike lanes; community gatherings and opportunities to teach citizens how to garden; and raised gardens for individuals who have limited back-yard space or need assistance with accessibility.

Some ideas that were shared during this discussion were: to have neighbourhood gardens, where neighbours would each grow a certain vegetable, and then share amongst themselves; having more good food boxes, and how to go about this (i.e. volunteering to help with the production of these boxes); encouraging trade among farmers; educating around herb gardens in kitchens and promoting cooking classrooms; and most importantly, how to go about involving children so that it would continue through the generations. [Student reflection]

\section{Diversity}

After a complex system has encountered a release of structure (e.g., following a forest fire), a diversity of resources and entities can now encounter one another in new ways. This diversity is key to the adaptation, innovation, and regrowth of the system (Page, 2011; Westley, Zimmerman \& Patton, 2006). Likewise, another reason that ecotones are characterized by abundance and innovation is the effect of diversity, as elements from different ecosystems encounter one another. Diversity is a key characteristic of CAS theory, as it creates the robustness needed for the emergence of self-organizing possibilities, adaptation to change, and resilience. In our Gatherings, the participants themselves brought diversity through their perspectives and also through their experiences rooted in their positions in society.

Diversity is also a key concept in the community development literature. For example, Born (2012 emphasizes the importance of diversity in creating community transformation. Dissent is recognized in Block's five conversations as critical to successful community conversations. By organizing our Gatherings to allow for dissent and doubt to emerge we fostered space for diversity in opin- 
ions to be expressed on the wicked problem. Expressions of dissent were simply respected. For example, some dissent was expressed that our Gatherings were futile, as a group of diversified community people can not possibly resolve this wicked problem because we have neither the power to convince the government to fund our ideas nor the financial capacity to advance those ideas. Perhaps the lack of labeling of participants fueled this dissent as many people may be more comfortable dealing with a wicked problem when they are aware of people's positions and thus consciously or unconsciously weighing the power in the room to create change. Or perhaps the lack of labeling was uncomfortable as the conversations at the Gatherings could not occur within the more typical dichotomous us-them framework. As Block cautions, dissent should not be answered as this can shut down diversity in opinions. Rather diversity conversations are times to listen and encourage expression of everyone's differing views.

The Gatherings encouraged this diversity by opening up participation from a wide sector of community people, holding the Gatherings in an accessible location with affordable bus transportation, and avoiding any "us and them" labeling.

It went without asking, that people had certain doubt about making these initiatives work amongst our community.... Thinking back to discussions with peers, particular individuals did hold views of disagreement, to which is their own right and choice. Overall, I found among my individual small group that there were more positive, empowering conversations taking place than not. Remember, "Dissent is a form of caring, not one of resistance." (quotation from Block, 2009, p. 136) [Student reflection]

\section{Connectivity}

Our journey through the back loop next involves the nurturing of connectivity among the diverse elements. Interconnectivity is a defining feature of any complex adaptive system; the behavior of the system as a whole emerges from the interconnections among its components (Hollings, 2001;
Meadows, 2008). Too often, outside experts or leaders in a traditional hierarchical organization may impose a rigid structure on the system's connections that is not well suited to the actual functioning of the system. In contrast, without this imposition, this connectivity from a complexity perspective may self-organize when individual elements in the system (people) choose the extent and type of connections they form. This connectivity then facilitates the emergence of a new form of structure. Nurturing the self-organization of connectivity among the diverse individual elements is critical to encouraging new ideas and new system behavior in light of our wicked problem.

Drawing on CAS theory, Lichtenstein, UhlBien, Marion, Seers, Orton, and Schreiber suggest that leadership occurs in the "spaces between agents" (2006, p. 3), and that by fostering a receptive environment, rather than imposing rigid structures and procedures, the leadership that emerges will not only be more reflective of the agents but also more adaptable, and therefore resilient as well. They refer to this form of leadership as emergent leadership (Lichtenstein et al., 2006). Similarly Block advocates for convening leadership that creates the social space for community engagement (Block, 2009).

Language can itself be considered a complex adaptive system (Steels, 2000), and the conceptual evolution that occurs during a group discussion can be understood as the co-evolution of an idea within the minds that have started it. Within the complexity perspective, there is no barrier between the development of an idea and the development of those who are discussing it. Ontology and epistemology lose their hard edges (Allen \& Varga, 2007). By embracing this co-evolution, we may promote conceptual growth within society by shaping the discussions we have.

This connectivity also enables individuals to see how the wicked problem of food access and farm viability appears to people in different social situations, and to recognize its connections with income, education, and well being as basic social determinants of health. In the Gatherings, it was important to carefully nurture connectivity that was not predefined by existing structure or imposed by outside leaders. 
Enhancing connectivity can also decrease the length of feedback loops. The need for tighter feedback loops, which connect the consequences of behavior to the people generating that behavior, has been identified by others studying local food systems (Clancy, 2013).

Connectivity is key to dialogue-based approaches to social change in the community development literature. McKnight and Block (2010) focus on the value of associational life whereby people are encouraged to enhance connectivity in addressing access to entrenched social issues. In other words, McKnight and Block find that social processes that encourage more community associations and connections have been found to be effective in addressing complex social problems. Likewise, Block's (2009) fourth and fifth conversations (Table 1) recognize the value of a focus on commitment and gifts to address the issue. For example, focusing on gifts and strengths, rather than deficiencies, needs, and deficits, creates a shift in the conversation about access to local nutritious food for vulnerable peoples and income sustainability for emerging farmers. Thus, focusing on gifts provides value to diversity and encourages connectivity and networking.

Truthfully, prior to taking this course and attending the Gathering, I was very naïve about the vulnerable people and emergency food assistance within my community. When I reflect on my story and the context in which I operated from, I saw the poverty, isolation and distress on the streets of Thunder Bay, but like many, I would just drive by and turn a blind eye to that world. When I was younger, and I wanted to do something "good", I was that person that thought they were doing an amazing, selfless deed by volunteering my time at the shelter house, handing out unappetizing food to the "homeless". Then it hits you and it hits you quite hard - I am a contributor of what is happening around me, I am a part of the cause, and I needed to change my current story. This course and Gathering encouraged me to create truth in my story and the stories that are presented to me. Escaping the "stuck community" mindset and seeing the world through a new lens, where I am accountable and own and exercise my power every time I show up. It is time to override the powerlessness as use of blame and dependency on others to make the change I wanted to see. For so long, with influence from family, peers, society, etc. poverty has been labeled as an individual problem; however I now recognize and understand that I am accountable for the well-being of the whole and acknowledge that a community is built by great citizens. I reclaimed my power, was a risk taker for the first time and become a creator of my community by offering my gifts and valuing others at the Gathering. I felt a part of something and had a sense of belonging among strangers, which is something that just evolved naturally throughout the Gathering. [Student reflection; emphasis in original]

As wonderful ideas were shared, a sense of relatedness and belonging was beginning to form and it became easier to ask questions, speak openly and take risks. This is where I began to recognize even more how my current story was sometimes hindering the possibility of an alternative future. I've never been a part of a community garden, spoke with local farmers or even participated in a community kitchen before but I knew there was something in me that I could use to contribute to this change. If this community is mine or ours to create, then where was my contribution? It was time to develop some personal power and not let someone else change this current reality, it was time I became involved in this transformation. [Student reflection]

\section{Active Engagement}

As the diverse new connections self-organize, potential solutions to the wicked problem, new ways of structuring relevant complex systems and their interactions, or innovative ideas begin to emerge. In order for this progression to occur, the 
elements within the system (people) must not only release existing structure, they must also engage actively with the process. One way that human complex systems may be different from other living systems, such as ant colonies, is that people, to varying degrees, can become conscious of how they participate in the emergence of particular patterns in their systems. This awareness, coupled with a willingness to make change, will be required in order for new patterns or solutions to emerge.

Block's (2009 conversation on ownership begins with the creation of a feedback loop whereby all participants can enhance their awareness of how they have contributed to the current reality of the wicked problem. Through this awareness a shift can occur from blaming the government or others for the current situation to becoming accountable for how our actions or lack of actions has contributed to the problem. In the Gatherings, we were careful to foster ownership by, for example, having no keynote or outside speaker. The emphasis was thus on engaging each participant as a valuable citizen producing the future, not waiting, begging for, or dreaming of the future (Block, 2009).

We were discussing why we were not "allowed" to consume whatever food products we wanted due to health regulations set out by government agencies. Each member at the table shared their personal story about struggles with these laws. One invitee mentioned that she would much rather drink and use unpasteurized milk, but is unable to find a supplier, as it is illegal to sell. Another invitee brought up the question as to why we don't have a chicken processing abattoir in Thunder Bay as she has chickens to sell, but cannot sell them unless they are alive and most people do not have the means to slaughter their own birds. A third person also questioned why we do not see wild game on more menus in Thunder Bay and why we do not have a restaurant that serves traditional Anishnawbe cuisine. After everyone shared their piece, the general consensus was why are we not able to select what we want to consume, sign a waiver releasing the producer and government of responsibility and do with our own bodies as we please? [Student reflection]

If you have a sense of belonging in your community, then you feel accountable for what you contribute. You are less likely to leave the responsibility of change to others and be conscious of your influence. Having the ownership conversation allowed me to see the reverse effect where accountability came first, and then I felt a greater sense of belonging. This was my experience anyway. I am a believer in change, but ownership, responsibility, and accountability had never been a starting point for me. I expect that others may have felt this as well, which put us in a good position for the community Gathering; we proceeded to open our mind to possibilities, while also feeling and seeing our position for change-making in it all. [Student reflection]

Block's (2010) final conversation on commitment involves the individual's choice to initiate change, even on a small scale. A commitment to change or action is essential if an extant system is to leave the back loop and progress to the forward loop of a new system.

\section{Conclusion}

According to Block, there is a "default" tendency for people to walk into a room assuming that all the happenings and the agenda belong to someone else. Our world is inundated with those who want to convince us about what we should believe and how we should act. Through a very deliberate setup, which included mindful awareness of how people were identified and welcomed, a welcoming physical space, and conversational tone, the Gatherings brought participants together on a journey through the back loop of the adaptive cycle. The Gatherings encouraged a shift toward a view that together we all have a legitimate role in creating our community. Block refers to this as moving the citizenship social contract from "parenting to partnership" (2010, p. 128). 
A unique paradox that is presented by using a wicked problem approach in gatherings such as these is that in order to foster a de-structured mind-set, we must carefully ensure that people are not identified by their roles at any time, from invitation through to the gatherings' dynamics. However, this makes it impossible to establish the role identities of the participants in attendance. Our experience with this process has revealed that any attempt to identify people by their formal roles (such as job titles or status as vulnerable) thwarts or inhibits the mental de-structuring so critical to opening a space for genuine dialogue. In holding this paradox, organizers of gatherings such as this must work carefully and extensively well in advance to reach out through formal and informal networks to ensure that there is the inclusiveness and diversity essential to the effectiveness of a gathering. With Block's (2010) five conversations as a guide, the Gatherings provided a dynamic space in which enough of the usual systems' structures were removed that people were able to release into a back-loop mindset. This mindset enabled open and innovative conversations that were fed with the diversity of perspectives that were deliberately brought into the conversation from local farmers to individuals living in vulnerable conditions. Ensuring access to local nutritious food for vulnerable people while also ensuring viable incomes for local farmers is a wicked problem emerging from the dynamics of multiple complex systems in interaction. Amelioration of this issue is going to require transformative, system-scale change. The purpose of this paper was to describe an approach to addressing wicked problems that enables community members to release some of the structure in existing systems and innovate potential solutions themselves. Future work with this model will be to study the transition from back loop to forward loop. In other words, once the existing structures have been released and a diversity of new connections among engaged agents have been formed, how do emerging ideas gain traction and develop into tangible, system-scale change?

The purpose of this paper was to draw on complex adaptive systems theory in applying a wicked problems approach to understanding dynamics within the food system. Future research in this area is needed to assess the effects of this approach on people's thinking and dialogue about the issues, as well as their capacity to innovate potential solutions in the changing landscape of the food system. This bottom-up, emergent approach to writing new systems' patterns may ultimately transform the domain of the problem and present viable alternative futures that are adapted to the local reality and enhance community well being.

\section{References}

Allen, P. M., \& Varga, L. (2007). Complexity: The coevolution of epistemology, axiology and ontology. Nonlinear Dynamics, Psychology, and Life Sciences, 11(1), 19-50. http://www.societyforchaostheory.org/ndpls/

Baker, L., Campsie, P., \& Rabinowicz, K. (2010). Menu 2020: Ten good food ideas for Ontario. Toronto: George Cedric Metcalf Charitable Foundation. Retrieved from http://metcalffoundation.com/wpcontent/uploads/2011/05/menu-2020.pdf

Ballamingle, P., \& Walker, S. M. L. (2013). Field of dreams: Just Food's proposal to create a community food and sustainable agriculture hub in Ottawa, Ontario. Local Environment, 18(5), 529-542. http://dx.doi.org/10.1080/13549839.2013.787975

Batie, S. S. (2008). Wicked problems and applied economics. American Journal of Agricultural Economics, 90(5), 1176-1191. http://dx.doi.org/10.1111/ j.1467-8276.2008.01202.x

Block, P. (2009). Community: The structure of belonging. San Francisco: Berrett-Koehler Publishers.

Born, P. (2012). Community conversations: Mobilizing the ideas, skills, and passion of community organizations, governments, businesses, and people (2 ${ }^{\text {nd }} \mathrm{Ed}$.). Toronto: BPS Books.

Brown, V. A., Harris, J. A., \& Russell, J. Y. (2010). Tackling wicked problems through the transdisciplinary imagination. London: Earthscan (from Routledge).

Brown, J., \& Isaacs, D. (2005). The world café: Shaping our futures through conversations that matter. San Francisco: Berrett-Koehler Publishers.

Clancy, K. (2013). Feedback loops. Journal of Agriculture, Food Systems and Community Development, 3(3), 5-7. http://dx.doi.org/10.5304/jafscd.2013.033.007

Conklin, J. (2005). Dialogue mapping: Building shared understanding of wicked problems (1 ${ }^{\text {st }} \mathrm{Ed}$.). Toronto: Wiley. 
Daedlow, K., Beckmann, V. \& Arlinghaus, R. (2011). Assessing an adaptive cycle in a social system under external pressure to change: the importance of intergroup relations in recreational fisheries governance. Ecology and Society, 16(2), Article 3. http://www.ecologyandsociety.org/vol16/iss2/ art3/

Diers, J. (2004). Neighborhood power: Building community the Seattle way. Seattle: University of Washington Press.

Dooley, K. J. (1997). A complex adaptive systems model of organizational change. Nonlinear Dynamics, Psychology, and Life Sciences, 1(1), 69-97. http://dx.doi.org/10.1023/A:1022375910940

Federation of Canadian Municipalities (FCM). (2010). Mending Canada's frayed social safety net: The role of municipal governments (Theme Report No. 6). Retrieved from http://www.fcm.ca/Documents/ reports/Mending Canadas Frayed Social Safety Net The role of municipal governments EN.pdf

Fischer, M., Hamm, M., Pirog, R., Fisk, J., Farbman, J., \& Kiraly, S. (2013). Findings of the 2013 National Food Hub Survey. Michigan State University Center for Regional Food Systems \& The Wallace Center at Winrock International. Retrieved from http://foodsystems.msu.edu/activities/food-hub$\underline{\text { survey }}$

Forbes, C. B., \& Harmon, A. H. (2008). Buying into community supported agriculture: Strategies for overcoming income barriers. Journal of Hunger \& Environmental Nutrition, 2(1), 66-80. http://dx.doi.org/10.1080/19320240801891479

Food Security Research Network [FSRN]. (2013). Community food gatherings. Retrieved from http://www.fsrn.ca/what/communityengagement/gatherings

Goldstein, J., Hazy, J. K. \& Lichtenstein, B. B. (2011). Complexity and the nexus of leadership: Leveraging nonlinear science to create ecologies of innovation. New York: Palgrave MacMillan.

Gunderson, L. H. \& Holling, C. S. (2002). Panarchy: Understanding transformations in buman and natural systems. Washington, D.C.: Island Press.

Head, B. W. (2008). Wicked problems in public policy. Public Policy, 3(2), 101-118. http://search. informit.com.au/documentSummary; $\mathrm{dn}=66288030$ 6504754;res=IELFSC
Headwaters Group. (2012). Overview of wicked problems: Strategies for difficult times. St. Paul, Minnesota: Author. Retrieved from http://partners4change. org/wp-content/uploads/2012/01/wickedproblems.pdf

Hinrichs, C., \& Kremer, K. S. (2002). Social inclusion in a Midwest local food system project. Journal of Poverty, 6(1), 65-90. http://dx.doi.org/10.1300/J134v06n01 04

Holling, C. S. (1986). The resilience of terrestrial ecosystems: Local surprise and global change. In W. C. Clark \& R. E. Munn (Eds.), Sustainable development of the biosphere (292-317). Cambridge, UK: Cambridge University Press.

Holling, C. S. (2001). Understanding the complexity of economic, ecological, and social systems. Ecosystems, 4(5), 390-405. http://dx.doi.org/10.1007/s10021$\underline{001-0101-5}$

Holman, P. (2010). Engaging emergence: Turning upheaval into opportunity. San Francisco: Berrett-Koehler.

Ikerd, J. (2005). Sustainable capitalism: A matter of common sense. Sterling, Virginia: Kumarian Press

Ikerd, J. (2012). The essentials of economic sustainability. Sterling, Virginia: Kumarian Press.

Kagan, C. (2007). Working at the 'edge': Making use of psychological resources through collaboration. The Psychologist, 20(4), 224-227.

http://www.thepsychologist.org.uk/archive/ archive home.cfm/volumeID 20-editionID 146ArticleID 1172-getfile getPDF/thepsychologist

Könnölä, T., Brummer, V., \& Salo, A. (2007). Diversity in foresight: Insights from the fostering of innovation ideas. Technological Forecasting and Social Change, 74(5), 608-626. http://dx.doi.org/10.1016/j.techfore.2006.11.003

Knezevic, I., \& Nelson, E. (2013). Introduction. In I. Knezevic, K. Landman, A. Blay-Palmer, \& E. Nelson (Eds.). Models and best practices for building sustainable food systems in Ontario and beyond (pp. 1-8). Guelph, Ontario: Ontario Ministry of Agriculture, Food and Rural Affairs. Retrieved from http://nourishingontario.ca/models-and-bestpractices/

Kunz, W., \& Rittel, H. W. J. (1970/1979). Issues as elements of information systems (Working Paper No. 131). Institute of Urban and Regional Development, University of California. 
Landman, K., Blay-Palmer, A., Kornelsen, S., Bundock, J., Nelson, E., Davis, M., Temple, K., \& Megens, S. (2009). Local food: From the ground up. Ontario Ministry of Agriculture and Rural Affairs Sustainable Rural Communities Initiative.

Lappé, F. M., Clapp, J., Anderson, M. Broad, R., Messer, E., Pogge, T., \& Wise, T. (2013). How we count hunger matters. Ethics \& International Affairs, 27(3), 251-259. http://dx.doi.org/10.1017/S0892679413000191

Lichtenstein, B. B., Uhl-Bien, M., Marion, R., Seers, A., Orton, J. D., \& Schreiber, C. (2006). Complexity leadership theory: An interactive perspective on leading in complex adaptive systems. Emergence: Complexity and Organization, 8(4), 2-12. http://emergentpublications.com/ECO/Contents. aspx

Lipmanowicz, H., \& McCandless, K. (2013). Liberating structures: Including and unleashing everyone. http://www.liberatingstructures.com/

Lipmanowicz, H., \& McCandless, K. (2014). The surprising power of liberating structures: Simple rules to unleash a culture of innovation. Seattle: Liberating Structures Press. http://www.liberatingstructures.com/bookstore/

Manson, S. M. (2001). Simplifying complexity: A review of complexity theory. Geoforum, 32(3), 405-414. http://dx.doi.org/10.1016/S0016-7185(00)00035X

Matson, J., Sullins, M., \& Cook, C. (2013). The role of food hubs in local food marketing (USDA Rural Development Service Report 73). Washington, D.C.: USDA Rural Development. Retrieved from http://www.ams.usda.gov/AMSv1.0/getfile?dDoc Name=STELPRDC5102827

McEntee, J. C., \& Naumova, E. N. (2012). Building capacity between the private emergency food system and the local food movement: Working toward food justice and sovereignty in the global North. Journal of Agriculture, Food Systems, and Community Development, 3(1), 235-253. http://dx.doi.org/10.5304/jafscd.2012.031.012

McKnight, J. \& Block, P. (2010). The abundant community: Awakening the power of families and neighborhoods. San Francisco: Berrett-Koehler Publishers.

Meadows, D. H. (2008). Thinking in systems: A primer. White River Junction, Vermont: Chelsea Green Publishing Company.
Nelson, C. H., \& Stroink, M. L. (2011). Food security and sovereignty. International Forum on the Social and Solidarity Economy - Government and Civil Society. Retrieved from http://www.reliess.org/wpcontent/uploads/2010/10/FIESS WP FoodSecurity-and-Sovereignty Oct.-2011.pdf

Nelson, C. H., \& Stroink, M. L. (2012). Food security and sovereignty in the social and solidarity economy. Universitas Forum, 3(2). http://www.universitasforum.org/index.php/ ojs/issue/view/8/showToc

Nelson, C. H., \& Stroink, M. L. (2013). Northern Ontario. In I. Knezevic, K. Landman, A. BlayPalmer, \& E. Nelson (Eds.). Models and best practices for building sustainable food systems in Ontario and beyond (pp. 16-67). Guelph, Ontario: Ontario Ministry of Agriculture, Food and Rural Affairs. Retrieved from http://nourishingontario.ca/models-andbest-practices/

Page, S. E. (2011). Diversity and complexity. Princeton, New Jersey: Princeton University Press.

People's Food Policy Project. (2011). Resetting the table: A people's food policy for Canada. Montreal: Food Secure Canada. Retrieved from http://foodsecurecanada. org/policy-advocacy/resetting-table

Risser, P. G. (1995). The status of the science examining ecotones. BioScience, 45(5), 318-325. http://dx.doi.org/10.2307/1312492

Rittel, H. W. J., \& Webber, M. M. (1973). Dilemmas in a general theory of planning. Policy Sciences, 4(2), 155169. http://dx.doi.org/10.1007/BF01405730

Roberts, N. C. (2000). Wicked problems and network approaches to resolution. International Public Management Review, 1(1), 1-19. http://www.ipmr.net

Steels, L. (2000). Language as a complex adaptive system. In M. Schoenauer, K. Deb, G. Rudolph, X. Yao, E. Lutton, J. J. Merelo, \& H.-P. Schwefel (Eds.), Parallel problem solving from nature PPSN VI: 6th international conference Paris, France, September 18 20, 2000 proceedings (17-26). Berlin: Springer. http://dx.doi.org/10.1007/3-540-45356-3 2

Stroink, M. L., \& Nelson, C. H. (2013). Complexity and food hubs: Five case studies from Northern Ontario. Local Environment: The International Journal of Justice and Sustainability, 18(5), 620-635. http://dx.doi.org/10.1080/13549839.2013.798635 
Walker, B., \& Salt, D. (2006. Resilience thinking: Sustaining ecosystems and people in a changing world. Washington, D.C.: Island Press.

Weber, E. P., \& Khademian, A. M. (2008). Wicked problems, knowledge challenges, and collaborative capacity builders in network settings. Public
Administration Review, 68(2), 334-349.

http://dx.doi.org/10.1111/j.15406210.2007.00866.x

Westley, F., Zimmerman, B., \& Patton, M. Q. (2006). Getting to maybe: How the world is changed. Toronto: Random House Canada. 